\title{
IMAGE ENHACEMENT PADA CITRA GESTUR TANGAN MENGGUNAKAN CONTRAST LIMITED ADAPTIVE HISTOGRAM EQUALIZATION
}

\author{
Natanael Christian Putra Windo Yustiantara ${ }^{1}$, Resty Wulanningrum ${ }^{2}$, Siti Rochana ${ }^{3}$ \\ Teknik Informatika, Fakultas Teknik, Universitas Nusantara PGRI Kediri \\ Jl. Ahmad Dahlan No. 76, Mojoroto, Kec. Mojoroto, Kota Kediri \\ Telp. 0813-3525-7409 \\ E-mail: natanaelismi@gmail.com ${ }^{1}$,resty0601@gmail.com ${ }^{2}$, sitirochana@unp.ac.id ${ }^{3}$
}

\begin{abstract}
ABSTRAKS
Image Enhacement merupakan proses perbaikan kualitas citra yang dilakukan dengan menggunakan beberapa metode. Citra yang paling sering dilakukan perbaikan kualitas adalah citra digital. Citra digital sering digunakan pada pengolahan citra biometrik, pengenalan wajah, pengenalan tanda tangan, bahkan permasalahan pada Closed Circuit Television (CCTV). Penelitian ini bertujuan untuk memberikan perbedaan hasil proses image enhacement pada gambar yang telah tertangkap oleh CCTV. Penelitian ini menggunakan 3 buah metode yaitu, Histogram Equalization (HE), Adaptive Histogram Equalization (AHE), dan Contrast Limited Adaptive Histogram Equalization (CLAHE) untuk melakukan perbaikan citra, sedangkan objek yang akan digunakan pada penelitian ini adalah citra gesture tangan. Dari hasil penelitian ini dapat dilihat bahwa Nilai MSE (Mean Squared Error) yang mendekatiangka 0 adalah gambar yang menggunakan metode CLAHE (Contrast Limited Adaptive Histogram Equalization) dengan nilai sebesar 653.5. Untuk nilai PSNR (Peak Signal to Noise Ratio)sendiri nilai yang paling besar yaitu 29.9783476895 dengan menggunakan metode CLAHE.
\end{abstract}

Kata Kunci: Image Enhacement, Citra GesturTangan, HE, AHE, CLAHE

\begin{abstract}
Image Enhancement is an image quality improvement process that is carried out using several methods. The image that is most often used for quality improvement is a digital image. Digital images are often used in biometric image processing, facial recognition, signature recognition, and even problems with Closed Circuit Television (CCTV). This study aims to provide differences in the results of the image enhancement process on images that have been captured by CCTV. This study uses 3 methods, namely, Histogram Equalization (HE), Adaptive Histogram Equalization (AHE), and Contrast Limited Adaptive Histogram Equalization (CLAHE) to improve the image, while the object that will be used in this study is the image of hand gestures. From the results of this study, it can be seen that the MSE (Mean Squared Error) value that is close to 0 is an image that uses the CLAHE (Contrast Limited Adaptive Histogram Equalization) method with a value of 653.5. For the PSNR (Peak Signal to Noise Ratio) value itself, the largest value is 29.9783476895 using the CLAHE method.
\end{abstract}

Keywords: Image Enhancement, Hand Gesture Image, HE, AHE, CLAHE

\section{PENDAHULUAN}

\subsection{Latar Belakang}

Permasalahan umum yang terjadi pada citra adalah hasil dari citra itu sendiri, apalagi citra yang dihasilkan dari tangkapan sebuah Closed Circuit Television $(C C T V)$. Tidak sedikit hasil citra yang ditangkap oleh CCTV kurang jelas dan sulit untuk dipahami oleh manusia atau petugas pemantau CCTV.

Beberapa elemen yang digunakan untuk dapat mendukung keberhasilan system CCTV, antara lain adalah:

1. Kamera : Berdasarkan kategori bentuk terbagi menjadi 2 macam yaitu fixed camera (posisi kamera tidak berubah) danPTZ (Pan Tilt Zoom) (posisi kamera dapat berubah dan dapat di zoom).
2. Media transmisi : Media transmisidari CCTV menggunakan kabel koaksial atau UTP sedangkan wireless menggunakan acces point berupa router.

3. Monitor : Menampilkan objek yang ditangkap oleh kamera.

4. Apilkasi Piranti Lunak : Suatu aplikasi yang dapat mengontrol CCTV dari suatu tempat dan dapat diinterogasikan dengan server penyimpanan video.

5. Media Penyimpanan : DVR (Digital Video Recorder) atau Harddisk.

Namun menurut beberapa penelitian menggambarkan masih kurang maksimalnya hasil gambar dari CCTV sehingga masih memerlukan 
perbaikan kualitas gambar pada CCTV (Astra, 2018).

Pada penelitian kali ini, peneliti ingin melakukan sebuah perbaikan citra (image enhacement) dengan objek sebuah citra gesture tangan. Image Enhacement merupakan langkah awal dalam proses pengolahan citra (Image-Prerocessing). Dalam melakukan image enhacement ini terdapat beberapa tantangan, antara lain bagaimana CCTV dapat mendapatkan citra dengan tepat, bagaimana mengimplementasikan metode CLAHE untuk citra. Perbaikan citra ini bertujuan agar hasil citra yang diperoleh bias lebih maksimal meskipun cahaya yang didapatkan pada CCTV tidak terlalu bagus, serta dapat mengimplementasikan metode CLAHE agak mendapatkan kualitas citra yang lebih maksimal.

Seiring berkembangnya waktu, banyak metodemetode yang dapat digunakan untuk melakukan perbaikan citra (Image Enhacement). Image Enhacement sendiri merupakan sebuah Ada 3 buah metode yang akan digunakan oleh peneliti untuk melakukan perbaikan citra, yaitu menggunakan metode Histogram Equalization (HE), Adaptive Histogram Equalization (AHE), dan Contrast Limited Adaptive Histogram Equalization (CLAHE), sementara untuk bahasa pemrogramannya sendiri peneliti menggunakan bahasa pemrograman Python.

\subsection{Referensi}

\subsubsection{Citra Digital}

Citra digital merupakan gambar 2 dimensi yang dihasilkan dari analog dua dimensi yang kontinu menjadi gambar melalui proses sampling. Gambar analog dibagi menjadi $\mathrm{N}$ bari dan $\mathrm{M}$ kolom sehingga menjadi gambar diskrit. Pixel mempunyai dua parameter, yaitu koordinat dan intensitas (warna). Nilai yang terdapat pada koordinat $(x, y)$ adalah $f(x, y)$, yaitu besar intensitasdari pixel di titik itu. Berikut bentuk matriks sebuah citra digital (Munantri, 2019):

$$
f=\left[\begin{array}{cccc}
f(1,1) & f(1,2) & \ldots & f(1, N) \\
f(2,1) & f(2,2) & \ldots & f(2, N) \\
\ldots & \ldots & \ldots & \ldots \\
f(M, 1) & f(M, 2) & \ldots & f(M, N)
\end{array}\right] \ldots \ldots(1)
$$

\subsubsection{Histogram Equalization (HE)}

Histogram Equalization (HE) adalah salah satu metode yang digunakan untuk meningkatkan kontras gambar yang diberikan. Gambar yang disempurnakan memiliki distribusi abu-abu yang seragam level. Hal ini berkaitan dengan jenis histogram dalam memperbaiki kontras secara berurutan. (Zakaria, dkk., 2019).

Tujuan utama dari perataan histogram adalah untuk memperoleh penyebaran histogram yang merata sehingga derajat keabuan memiliki jumlah pixel yang relatif sama. Karena histogram menyatakan peluang pixel dengan derajat keabuan tertentu maka rumus menghitung perataan histogram adalah sebagai berikut:

$P_{r}\left(r_{k}\right)=\frac{n_{k}}{n}$ dalam hal ini $r_{k}=\frac{k}{L-1} .0 \leq \mathrm{k} \leq \mathrm{L}-$ 1....(2)

Artinya derajat keabuan (k) dinormalkan terhadap derajat keabuan terbesar (L-1). Nilai $r_{k}=0$ menyatakan hitam, dan $r_{k}=1$ menyatakan putih dalam skala keabuan yang didefinisikan (Kusuma, 2020).

\subsubsection{Adaptive Histogram Equalization (AHE)}

Adaptive Histogram Equalization (AHE) pada prinsipnya sama dengan Histogram Equalization (HE), yaitu mengerjakan proses ekualisasi histogram sebanyak beberapa kali masing-masing untuk setiap blok citra (subimage). Ukuran blok citra telah ditentukan sesuai kondisi citra atau kebutuhan penelitian, yaitu antara lain $2 \times 2$ pixel, $4 \times 4$ pixel, $8 \times 8$ pixel, 16x16 pixel, atau ukuran yang lain (Hidayat, 2019).

\subsubsection{Contrast Limited Adaptive Histogram Equalization (CLAHE)}

Kontras adalah tingkat penyebaran pixel-pixel ke dalam intensitas warna. Ada 3 macam kontras, yaitu kontras rendah, kontras tinggi dan kontras normal.

a. Citra kontras rendah

Citra kontras rendah dicirikan dengan sebagian besar komposisi citranya adalah terang atau sebagian besar gelap. Tetapi, mungkin saja suatu citra tergolong kontras rendah meskipun tidak terlalu terang atau tidak terlalu gelap bila semua pengelompokan nilai keabuan berada ditengah-tengah. Citra kontras rendah dapat diperbaiki kualitasnya dengan operasi peregangan kontras, melalui operasi ini, nilai-nilai keabuan pixel akan merentang dari 0 sampai 255.

b. Citra kontras tinggi

Citra kontras tinggi memiliki nilai jangkauan nilai keabuan yang lebar, tetapi terdapat area yang lebar yang didominasi oleh warna gelap dan area yang lebar yang didominasi oleh warna terang.

c. Citra kontras normal

Citra kontras normal memperlihatkan jangkauan nilai keabuan yang lebar tanpa ada nilai keabuan yang mendominasi (Sugiarti, 2018).

\subsubsection{MSE (Mean Squared Error)}

Mean Squared Error (MSE) adalah metode yang digunakan untuk mengukur kontrol dan kualitas sebuah citra. Nilai MSE dihitung dengan cara membandingkan sebuah objek contoh dengan objek 
aslinya, sehingga bisa diketahui tingkat ketidaksesuaiannya. Nilai MSE yang dihasilkan apabila semakin rendah dan mendekati 0 (nol), maka akan semakin mirip dengan citra aslinya dan bagus kualitas citra tersebut. Secara sistematis nilai MSE dapat dirumuskan sebagai berikut (Tinaliah, 2020):

$M S E=\frac{1}{m \times n}=\sum_{i=0}^{n-1} \sum{ }_{j=0}^{m-1}[f(i, j)-g(i, j)]^{2}$

\subsubsection{PSNR (Peak Signal to Noise Ratio)}

Peak Signal to Noise Ratio (PSNR) merupakan nilai perbandingan antara nilai maksimum warna citra hasil filtering dengan kuantitas gangguan (noise), yang dinyatakan dalam satuan desibel (dB), noise yang dimaksud adalah akar rata-rata kuadrat nilai kesalahan. Secara sistematis, nilai PSNR dapat dirumuskan sebagai berikut (Sidik, 2019):

PSNR $=10 \log _{10} \frac{M A X^{2}}{M S E}$

Keterangan :

m,n : Dimensi citra yang akan diproses

$f(i, j)$ : Nilai pixel citra asli pada koordinat $(i, j)$

$\mathrm{g}(\mathrm{i}, \mathrm{j})$ : Nilai pixel citra hasil perbaikan pada koordinat $(\mathrm{i}, \mathrm{j})$

MAXi : Nilai pixel maksimum pada citra asli

\subsubsection{Closed Circuit Television (CCTV)}

Closed Circuit Television (CCTV) merupakan sebuah perangkat kamera video digital yang digunakan untuk mengirim sinyal ke layar monitor disuatu ruang atau tempat tertentu, sehingga dapat mencegah terjadinya kejahatan atau dapat dijadikan sebagai bukti tindak kejahatan yang telah terjadi. Pada umumnya CCTV seringkali digunakan untuk mengawasi area publik seperti bank, hotel, bandara, gudang militer, pabrik, maupun pergudangan (Tantoni, 2020).

Selain ditempat-tempat umum, CCTV juga digunakan untuk menjaga rumah atau ruang penyimpanan gudang untuk menjaga informasi atau properti di dalamnya. Tanpa harus menempatkan banyak tenaga kerja terpercaya di setiap sudut ruangan yang harus dijaga, CCTV dapat memantau setiap ruangan dengan sebuah monitor (Ahda, 2018).

\subsubsection{Bahasa Pemrograman Python}

Python merupakan bahasa pemrograman tingkat tinggi. Pyhton dibuat oleh Guido van Rossum di Centrum Wiskunde \& Informatika (CWI), Belanda dan pertama kali dirilis pada tahun 1991. Python dapat dipergunakan untuk proyek skala kecil maupun skala besar. Saat ini python sudah mencapai versi $3 \mathrm{x}$ dan dapat digunakan untuk berbagai kebutuhan seperti web develeopment, GUI development, scientific, software development, dan system administration (Pinata, 2020)

Beberapa kelebihan dari bahasa pemrograman python diantara lain:

1. Pengembangan program dilakukan dengan cepat dan coding yang lebih sedikit

2. Mendukung multi platform

3. Memiliki sistem pengelolaan memori yang otomatis

4. Python bersifat Object Oriented Programming (OOD) (Ginting, 2020).

\section{PEMBAHASAN \\ 2.1 Kebutuhan Data \\ 2.1.1 Data Input}

Padapenelitian kali ini, peneliti akan menggunakan data gambar tangan mengepal dan terbuka untuk bahan penelitian. Data citra tangan diperoleh melalui proses foto dari tangan peneliti dan juga beberapa orang disekitar peneliti.

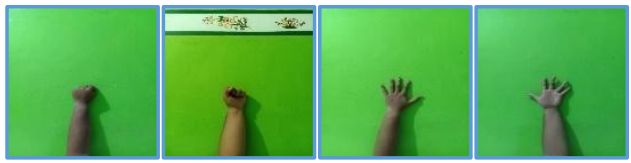

Gambar 1. Data Citra Tangan

\subsection{Metodologi Penelitian}

Penelitian ini menempuh langkah-langkah seperti yang dapat dilihat pada Gambar 1.

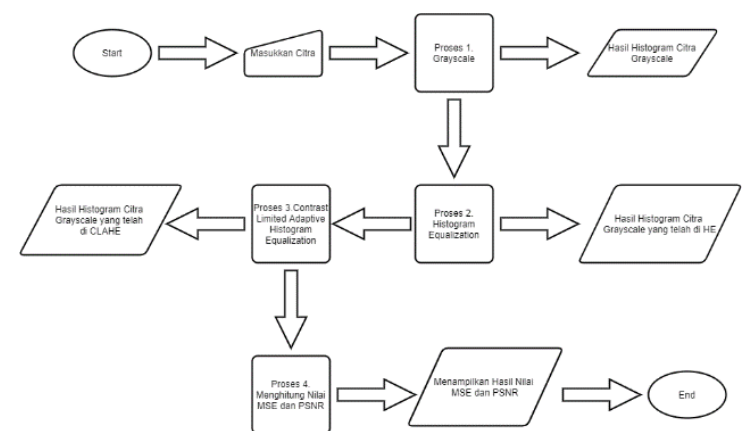

Gambar 2. Alur Penelitian

Keterangan:

Masukkan Citra

Pada tahap ini, citra hasil capture dari CCTV dimasukkan untuk dijadikan citra training. Citra diambil sebanyak 4 data, 2 data gesture tangan mengepal dan 2 data gesture tangan terbuka.

\section{Proses 1 Grayscale}

Pada tahap ini, mengubah citra asli yang telah dihasilkan menjadi citra abu-abu atau citra grayscale yang nanti akan menjadi bahan untuk dilakukan pengolahan. Serta menampilkan histogram dari citra yang telah dilakukan grayscale.

\section{Proses 2 Histogram Equalization}

Pada tahap ini, citra yang telah dirubah menjadi citra grayscale kemudian dilakukan proses perbaikan citra dengan metode Histogram Equalization serta menampilkan histogram hasil citra yang telah dilakukan enhacement dengan Histogram Equalization. 
Proses 3 Adaptive Histogram Equalization

Pada tahap ini, citra yang telah dirubah menjadi citra grayscale kemudian dilakukan proses enhacement dengan menggunakan metode Adaptive Histogram Equalization, serta menampilkan histogram hasil citra yang telah dilakukan enhacement dengan Adaptive Histogram Equalization.

Proses 4 Contrast Limited Adaptive Histogram Equalization

Pada tahap ini, citra yang telah dirubah menjadi citra grayscale kemudian dilakukan proses enhacement dengan menggunakan metode Contrast Limited Adaptive Histogram Equalization, serta menampilkan histogram hasil citra yang telah dilakukan enhacement dengan Contrast Limited Adaptive Histogram Equalization.

\section{Proses 5 Menghitung Nilai MSE dan PSNR}

Pada tahap ini, adalah tahapan mencari nilai MSE dan PSNR dari masing-masing data yang telah dilakukan proses enhacement, untuk menentukan metode mana yang mendekati baik untuk selanjutnya dapat direkomendasikan agar digunakan.

\subsection{Perangkat Uji Coba}

Perangkat yang digunakan untuk ujicoba pada penelitian ini meliputi perangkat keras dan perangkat lunak. Untuk dapat melihat perangkat keras dan perangkat lunak lebih spesifik terdapat pada Table 1.

\section{Table 1. Perangkat Uji Coba}

\begin{tabular}{|ll|ll|}
\hline \multicolumn{2}{|l|}{ Perangkat Keras } & \multicolumn{2}{|c|}{ Perangkat Lunak } \\
\hline 1. & Prosessor : Intel & 1. & Sistem Operasi : \\
& Core i5-8250U & & Windows 10 Home \\
& CPU @ 3.4 GHz & & Single Language \\
2. & Memory : Ram 8 & & 64-bit \\
& GB & 2. & IDLE : Python 3.9 \\
3. & Kamera : & & (64-bit) \\
& Handphone Oppo \\
& F9 & \\
4. & & \\
& Harddiks : HDD & & \\
\hline
\end{tabular}

\subsection{Skenario Uji Coba}

Ujicoba dilakukan untuk mengetahui hasil citra dari proses enhacement dengan menggunakan 3 buah metode Histogram Equalization, Adaptive Histogram Equalization, dan Contrast Limited Adaptive Histogram Equalization. Serta untuk mengetahui nilai dari MSE (Mean Squared Error) dan PSNR (Peak Signal to Noise Ratio) dari data yang akan dilakukan proses ujicoba. Data yang akan digunakan untuk ujicoba berupa 2 buah jenis gambar gesture tangan yaitu gesture tangan mengepal dan gesture tangan terbuka sebanyak masing-masing 2 buah. Peneliti menghasilkan 4 buah scenario berdasarkan jumlah data. Skenario dapat dilihat pada Table 2, 3, 4, dan 5 .

Tabel 2. Skenario 1

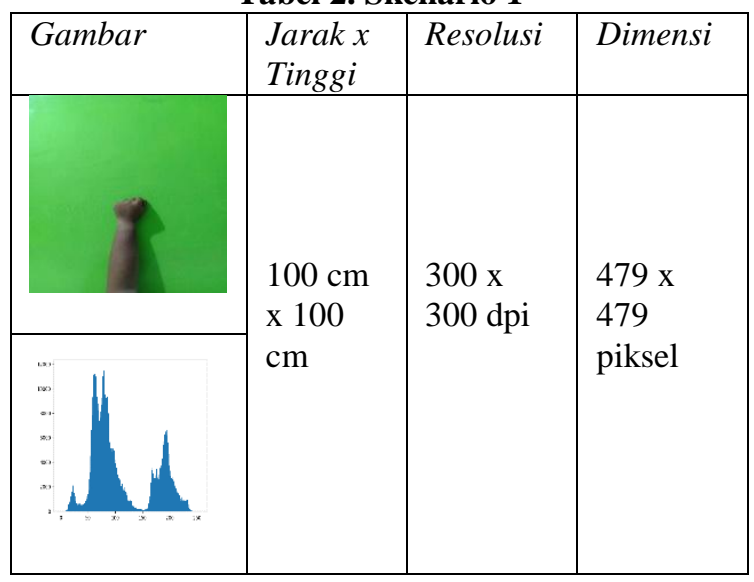

Tabel 3. Skenario 2

\begin{tabular}{|c|l|l|l|}
\hline Gambar & $\begin{array}{l}\text { Jarakx } \\
\text { Tinggi }\end{array}$ & Resolusi & Dimensi \\
\hline & & & \\
\hline & $\begin{array}{l}100 \mathrm{~cm} \\
\mathrm{x} 100 \\
\mathrm{~cm}\end{array}$ & $\begin{array}{l}96 \times 96 \\
\mathrm{dpi}\end{array}$ & $\begin{array}{l}526 \mathrm{x} \\
702 \\
\text { piksel }\end{array}$ \\
& & & \\
& & & \\
\hline & & & \\
\hline
\end{tabular}

Tabel 4. Skenario 3

\begin{tabular}{|l|l|l|l|}
\hline Gambar & $\begin{array}{l}\text { Jarakx } \\
\text { Tinggi }\end{array}$ & Resolusi & Dimensi \\
\hline & & & \\
& $100 \mathrm{~cm}$ & $150 \mathrm{x}$ & $347 \mathrm{x}$ \\
& $\mathrm{x} 100$ & $150 \mathrm{dpi}$ & $\begin{array}{l}463 \\
\text { piksel }\end{array}$ \\
\hline & $\mathrm{cm}$ & & \\
\hline & & & \\
\hline
\end{tabular}

Tabel 5. Skenario 4

\begin{tabular}{|l|l|l|l|}
\hline Gambar & $\begin{array}{l}\text { Jarakx } \\
\text { Tinggi }\end{array}$ & Resolusi & Dimensi \\
\hline & & & \\
& & & \\
\hline
\end{tabular}




\begin{tabular}{|l|l|l|l|}
\hline & $\begin{array}{l}100 \mathrm{~cm} \\
\text { x } 100\end{array}$ & $\begin{array}{l}96 \times 96 \\
\text { dpi }\end{array}$ & $\begin{array}{l}300 \mathrm{x} \\
300 \\
\text { piksel }\end{array}$ \\
& $\mathrm{cm}$ & & \\
\hline
\end{tabular}

\subsection{Hasil Uji Coba}

Ujicoba pada penelitian ini, peneliti memisahkan setiap scenario dilakukan image enhacement dengan merubah menjadi citra Grayscale terlebih dahulu, selanjutnya melakukan perbaikan citra menggunakan metode Histogram Equalization, Adaptive Histogram Equalization, dan Contrast Limited Adaptive Histogram Equalization. Hasil dari ujicoba pada penelitian ini dapat dilihat pada Tabel $6,7,8$, dan 9 .

Tabel 6. Hasil Uji Coba Skenario 1

\begin{tabular}{|c|c|c|}
\hline Citra Tangan & Nilai MSE & Nilai PSNR \\
\hline & $\begin{array}{l}1138.16666666 \\
66667\end{array}$ & $\begin{array}{l}27.568744984 \\
1\end{array}$ \\
\hline$=$ & \multicolumn{2}{|c|}{ Histogram Citra Grayscale } \\
\hline & 4343.5 & $\begin{array}{l}21.752405350 \\
2\end{array}$ \\
\hline & \multicolumn{2}{|c|}{$\begin{array}{l}\text { Histogram Citra Histogram } \\
\text { Equalization }\end{array}$} \\
\hline & $\begin{array}{l}1307.83333333 \\
33333\end{array}$ & $\begin{array}{l}26.965279587 \\
5\end{array}$ \\
\hline 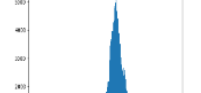 & \multicolumn{2}{|c|}{$\begin{array}{l}\text { Histogram Citra Adaptive } \\
\text { Histogram Equalization }\end{array}$} \\
\hline & $\begin{array}{l}945.833333333 \\
3334\end{array}$ & 28.372657454 \\
\hline 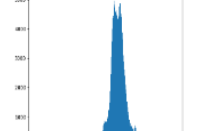 & \multicolumn{2}{|c|}{$\begin{array}{l}\text { Histogram Citra Contrast } \\
\text { Limited Adaptive Histogram } \\
\text { Equalization }\end{array}$} \\
\hline
\end{tabular}

Dari Tabel 6 dapat dilihat bahwa Nilai MSE (Mean Squared Error) yang mendekati angka 0 adalah gambar 4 yang menggunakan metode CLAHE (Contrast Limited Adaptive Histogram Equalization) dengan nilai sebesar 945.8333333333334. Untuk nilai PSNR (Peak Signal to Noise Ratio) sendiri dari ke 4 gambar yang paling besar adalah gambar nomor 4 , yaitu sebesar 28.372657454.

Tabel 7. Hasil Uji Coba Skenario 2

\begin{tabular}{|c|c|c|}
\hline Citra Tangan & Nilai MSE & Nilai PSNR \\
\hline 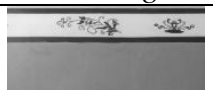 & 6890.5 & $\begin{array}{l}19.748296238 \\
1\end{array}$ \\
\hline & Histogram CitraGr & yscale \\
\hline 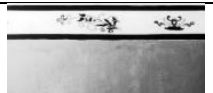 & $\begin{array}{l}29291.666666666 \\
668\end{array}$ & $\begin{array}{l}13.463362775 \\
1\end{array}$ \\
\hline & $\begin{array}{l}\text { Histogram CitraHi } \\
\text { Equalization }\end{array}$ & togram \\
\hline Why & $\begin{array}{l}7475.1666666666 \\
67\end{array}$ & $\begin{array}{l}19.394594806 \\
9\end{array}$ \\
\hline$=$ & $\begin{array}{l}\text { Histogram CitraAd } \\
\text { Histogram Equaliz }\end{array}$ & $\begin{array}{l}\text { aptive } \\
\text { tion }\end{array}$ \\
\hline 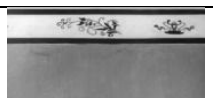 & 4616.0 & $\begin{array}{l}21.488145607 \\
2\end{array}$ \\
\hline & \multicolumn{2}{|c|}{$\begin{array}{l}\text { Histogram CitraContrast Limited } \\
\text { Adaptive Histogram Equalization }\end{array}$} \\
\hline
\end{tabular}

Dari Tabel 7 dapat dilihat bahwa Nilai MSE (Mean Squared Error) yang mendekati angka 0 adalah Gambar 4 yang menggunakan metode CLAHE (Contrast Limited Adaptive Histogram Equalization) dengan nilai sebesar 4616.0. Untuk nilai PSNR (Peak Signal to Noise Ratio) sendiri dari 
ke 4 gambar yang paling besar adalah gambar nomor 4, yaitu sebesar $\mathbf{2 1 . 4 8 8 1 4 5 6 0 7 2}$.

Tabel 8. Hasil Uji Coba Skenario 3

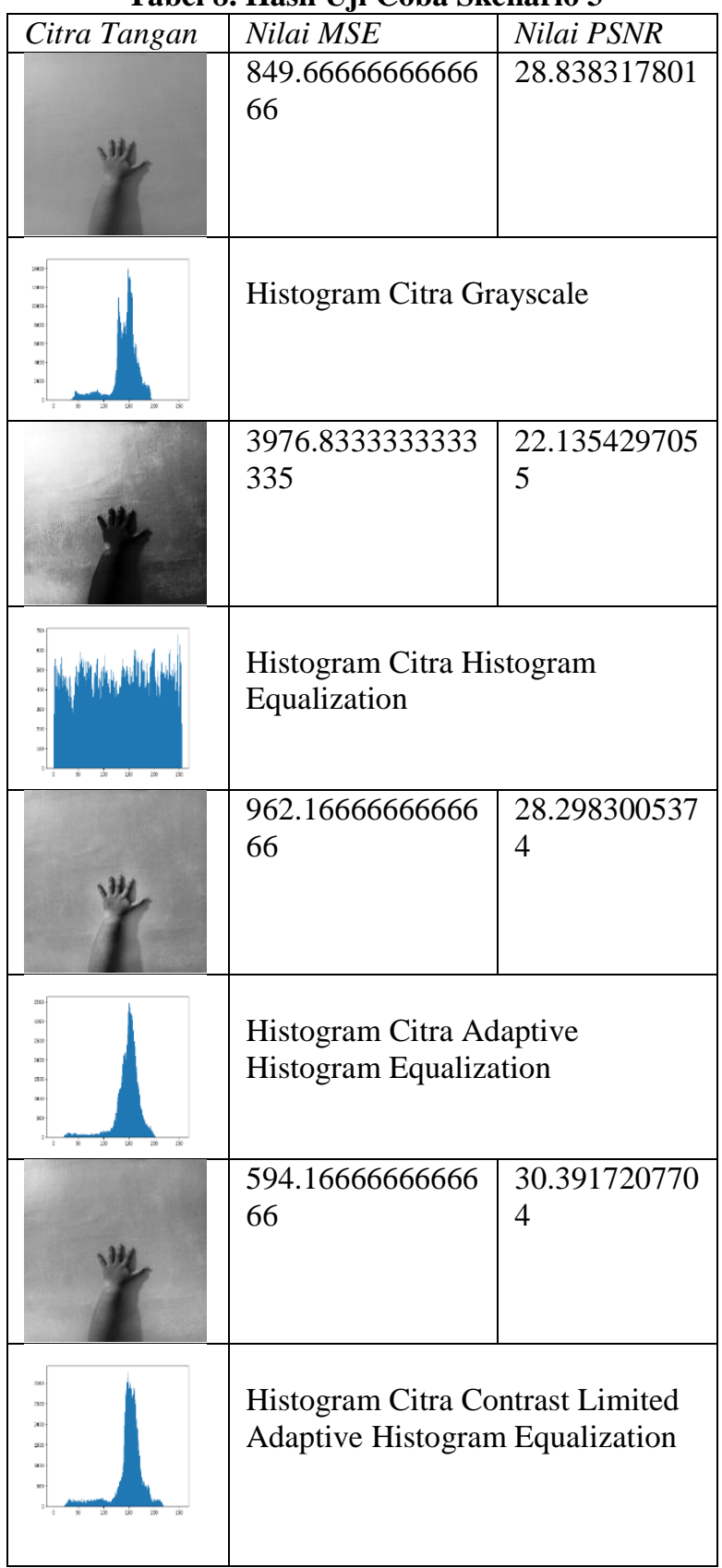

Dari Tabel 8 dapat dilihat bahwa Nilai MSE (Mean Squared Error) yang mendekati angka 0 adalah Gambar 4 yang menggunakan metode CLAHE (Contrast Limited Adaptive Histogram Equalization) dengan nilai sebesar 594.1666666666666. Untuk nilai PSNR (Peak Signal to Noise Ratio) sendiri dari ke 4 gambar yang paling besar adalah gambar nomor 4, yaitu sebesar 30.3917207704.
Tabel 9. Hasil Uji Coba Skenario 4

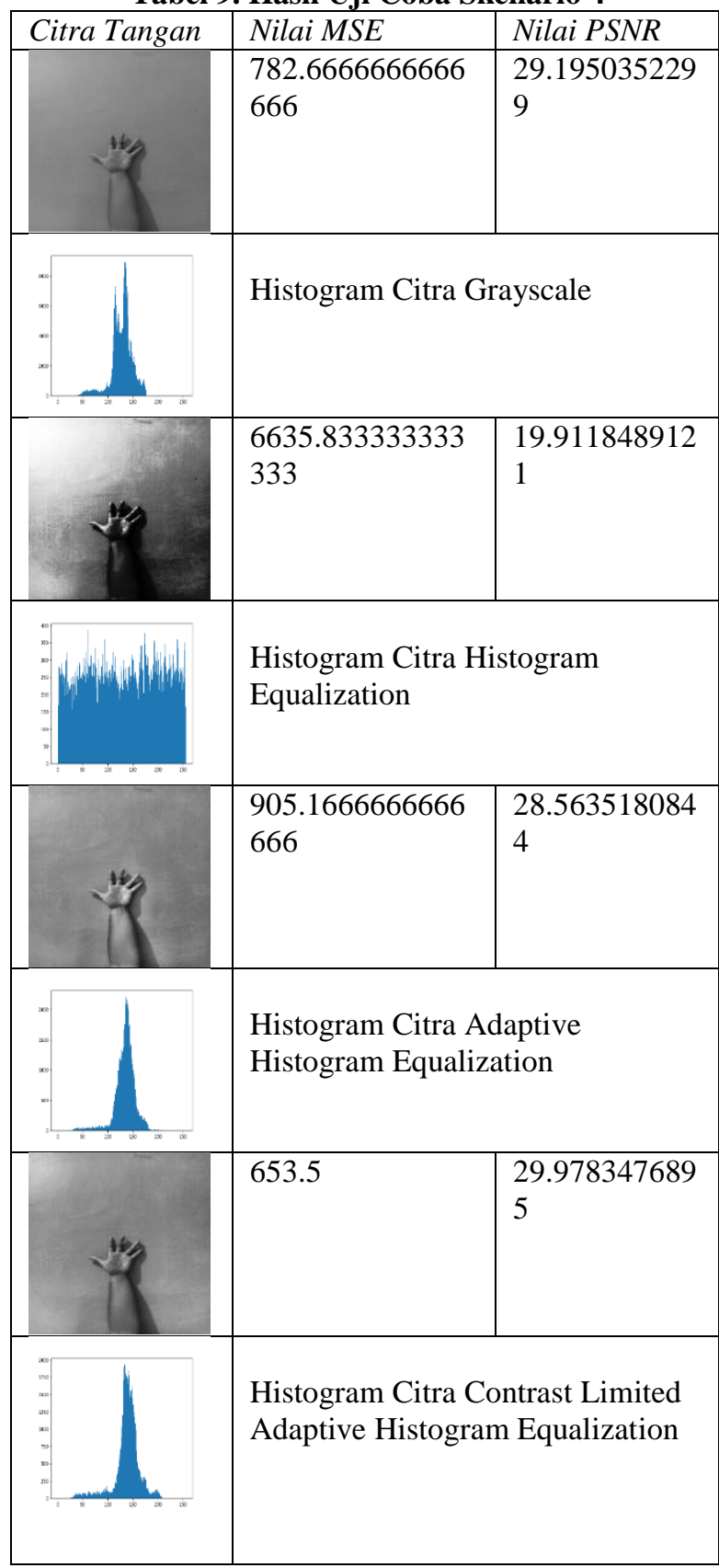

Dari Tabel 9 dapat dilihat bahwa Nilai MSE (Mean Squared Error) yang mendekati angka 0 adalah gambar 4 yang menggunakan metode CLAHE (Contrast Limited Adaptive Histogram Equalization) dengan nilai sebesar 653.5. Untuk nilai PSNR (Peak Signal to Noise Ratio) sendiri dari ke 4 gambar yang paling besar adalah gambar nomor 4, yaitu sebesar $\mathbf{2 9 . 9 7 8 3 4 7 6 8 9 5}$.

\section{KESIMPULAN}

Dari analisa hasil ujicoba pada ke 3 metode yang telah dilakukan oleh penulis, maka dapat disimpulkan sebagai berikut:

1. Metode yang paling baik digunakan untuk image enhacement yaitu dengan 
menggunakan metode Contrast Limited Adaptive Histogram Equalization (CLAHE).

2. Dengan menggunakan metode CLAHE maka nilai MSE pada citra akan semakin rendah mendekati 0 (nol).

3. Nilai PSNR dengan menggunakan metode CLAHE semakin besar, berarti menunjukkan hasil citra yang diperoleh semakin mirip dengan citra aslinya.

\section{PUSTAKA}

Ahda, A. 2018. Analisa Perbandingan Kinerja CCTV DVR dengan CCTV Portable Menggunakan Smartphone Android Secara Online. Jurnal Perencanaan, Sains, Teknologi, dan Komputer. Vol 1, No. 2.

Astra, O.A., Mardiana, Y. 2018. Rancang Bangun dan Analisa Pengendali CCTV Berbasis Arduino Menggunakan Smartphone Android. Jurnal Media Infotama. Vol 14, No. 1.

Ginting, V.S., Kusrini.,Luthfi, E.T. 2020. Penerapan Algoritma C4.5 Dalam Memprediksi Keterlambatan Pembayaran uang Sekolah Menggunakan Python. Jurnal Teknologi Informasi. Vol 4, No. 1.

Hidayat, J., Usman., Faisal, A., Syafriwel. 2019. Perbandingan Metode Perbaikan Kualitas Citra Berbasis Histogram Equalization Pada Citra Satelit. Journal Of Electrical Technology. Vol 4, No. 3.

Kusuma, I.W.A.W., Kusumadewi, A. 2020. Penerapan Metode Contrast Streching, Histogram Equalization dan Adaptive Histogram Equalization Untuk Meningkatkan Kualitas Citra Medis MRI. Jurnal SIMETRIS. Vol 11, No.1.

Munantri, N.Z., Sofyan, H., Yanu, M. 2019. Aplikasi Pengolahan Citra Digital Untuk Identifikasi Umur Pohon. TELEMATIKA. Vol 16, No. 2.

Piñata, N.N.P., Sukarsa, I.M., Rusjayanthi, N.K.D. 2020. Prediksi Kecelakaan Lalu Lintas Di Bali Dengan XGBoost Pada Python. Jurnal Ilmiah Merpati. Vol 8, No. 3.

Sidik.,Firmansyah., Anwar, S. 2019. Perbaikan Citra Malam (Tidak Infrared) Dengan Metode Histogram Equalization Dan Contrast Stretching. Jurnal Ilmu Pengetahuan dan Teknologi Komputer. Vol 4, No. 2.

Sugiarti. 2018. Peningkatan Kualitas Citra Dengan Metode Fuzzy Possibility Distribution. ILKOM Jurnal Ilmiah. Vol 10, No. 1.

Tantoni, A., Zaen, M.T.A. 2020. Sistem Keamanan Pemantauan CCTV Online Berbasis Android Pada Rumah Cantik Syifa Masbagik. JurnalInformatika\&RekayasaElektronika. Vol 2, No. 1.

Tinaliah., Elizabeth, T. 2020. Peningkatan Kualitas Citra X-Ray Paru-Paru Pasien Covid-19 Menggunakan Metode Contrast Limited
Adaptive Histogram Equalization. Jurnal Teknologi Informasi. Vol 4, No. 2.

Zakaria, A.I., Ernawati.,Vatresia, A., Oktoeberza, W.KZ. 2019. Perbandingan Metode HighFrequency Emphasis (HFE) dan Contrast Limited Adaptive Histogram Equalization (CLAHE) Dalam Perbaikan Kualitas Citra Penginderaan Jauh (Remote Sensing). Jurnal Pseudocode. Vol VI, No. 2. 